\title{
Two decades of aortic coarctation treatment in children; evaluating techniques
}

\author{
E. J. Dijkema · L. Dik · J. M. P. Breur · G. T. Sieswerda · F. Haas · M. G. Slieker · P. H. Schoof
}

Accepted: 20 October 2020 / Published online: 11 November 2020

(C) The Author(s) 2020

\begin{abstract}
Objective This study focuses on the evolution of treatment techniques for aortic coarctation in children and assesses long-term morbidity.

Methods This retrospective cohort study evaluates patients treated for native aortic coarctation, with at least 7 years of follow-up. To assess time-related changes, three time periods were distinguished according to year of primary intervention (era 1, 2 and 3). Operative and long-term follow-up data were collected by patient record reviews.

Results The study population consisted of 206 patients (177 surgical and 29 catheter-based interventions), with a median follow-up of 151 months. Anterior approach with simultaneous repair of aortic arch and associated cardiac lesions was more common in the most recent era. Median age at intervention did not change over time. Reintervention was necessary in one third of the cohort with an event-free survival of $74 \%$ at 5 -year and $68 \%$ at 10 -year follow-up. Reintervention rates were significantly higher after catheterbased interventions compared with surgical interventions (hazard ratio [HR] 1.8, 95\% confidence interval
\end{abstract}

E.J. Dijkema and L. Dik contributed equally to the manuscript.

E. J. Dijkema $(\varangle) \cdot$ L. Dik · J. M. P. Breur · M. G. Slieker

Department of Pediatric Cardiology, Wilhelmina Children's

Hospital (WKZ), University Medical Center Utrecht, Utrecht,

The Netherlands

ellesdijkema@gmail.com

G. T. Sieswerda

Department of Cardiology, University Medical Center Utrecht, Utrecht, The Netherlands

F. Haas $\cdot$ P. H. Schoof

Department of Cardiothoracic Surgery, Wilhelmina

Children's Hospital (WKZ), University Medical Center

Utrecht, Utrecht, The Netherlands
[CI] 1.04-3.00, $p=0.04$ ) and in patients treated before 3 months of age (HR 2.1, 95\% CI 1.27-3.55, $p=0.003$ ). Hypertension was present in one out of five patients. Conclusion Nowadays, complex patients with associated cardiac defects and arch hypoplasia are being treated surgically on bypass, whereas catheterbased intervention is introduced for non-complex patients. Reintervention is common and more frequent after catheter-based intervention and in surgery under 3 months of age. One fifth of the 206 patients remained hypertensive.

Keywords Congenital heart disease - Coarctation • Cardiothoracic surgery · Endovascular stent placement

\section{Introduction}

Coarctation of the aorta (CoA) is a relatively common congenital anomaly, responsible for $5-10 \%$ of all congenital heart defects [1-3]. The first documented therapy for CoA was in 1945; surgical resection of the narrowed segment followed by end-to-end anastomosis [4]. Over the past decades surgical techniques

\section{What's new?}

- Patients with more complex aortic coarctation and/or associated cardiac lesions are treated successfully with a more radical approach to concomitant treatment of the aortic-arch.

- Despite improved diagnosis, age at referral has not changed over time.

- Despite evolution of treatment strategies need for reintervention remains frequent.

- Hypertension is common in long-term follow-up despite adequate treatment of coarctation. 
have been modified and catheter-based intervention of CoA has been introduced as an alternative to surgery in both children and older patients $[2,5,6]$. Despite anatomically successful repair, patients are reported to have a reduced life expectancy, attributed to complications later in life, including hypertension, aneurysm formation, aortic dissection and rupture, and reinterventions [1, 3, 6, 7]. Therefore, long-term follow-up is recommended. This study focused on the long-term evolution of techniques in patients treated for native CoA. We present our experience from 1986 to 2010 .

\section{Methods}

\section{Study population}

Patient characteristics are depicted in Tab. 1. We included patients treated at our centre (the Wilhelmina Children's Hospital, Utrecht, the Netherlands) for native CoA at the age of $<18$ years with at least 7 years of follow-up (= intervention before 2010). Patients were grouped based on year of treatment: era 1 (1987-1994), era 2 (1995-2002) and era 3 (2003-2010), and split according to treatment strategy: surgery (end-to-end anastomosis, extended end-to-end anastomosis, patch angioplasty, aortic arch reconstruction and interposition graft) versus catheter-based interventions (balloon angioplasty with or without endovascular stent placement). Data on long-term follow-up were acquired from patients' medical records. A hypoplastic aortic arch was defined as a proximal or distal transverse arch diameter less than $60 \%$ or $50 \%$ of the diameter of the ascending aorta, respectively [8].

The Medical Ethics Committee of the University Medical Center Utrecht has decided that the official approval of this study by the Medical Ethics Committee was not required.

\section{Treatment strategies}

Surgical repair with end-to-end anastomosis was performed through either a lateral thoracotomy without use of extracorporeal circulation or a median sternotomy with the use of extracorporeal circulation, in the presence of hypoplastic aortic arch and/or associated cardiac defects. In the early years, patch angioplasty was performed through a lateral thoracotomy without the use of extracorporeal circulation. Over the years, a primary approach was favoured with a median sternotomy and aortic arch reconstruction with a patch and use of extracorporeal circulation, defined as arch reconstruction. Catheter-based treatment consisted of balloon angioplasty with or without stent placement. The technique was introduced at our centre in 1990 and supplemented with stent placement in 2008.

\section{Follow-up data}

Follow-up focused on reintervention rate (catheterbased or surgical), presence of hypertension and aortic arch aneurysm formation in the patients who underwent computed tomography (CT) or magnetic resonance imaging during follow-up. Reference values for hypertension were based on those reported by Wuhl et al. [9].

\section{Statistical analysis}

Statistical analyses were performed using IBM SPSS Statistics, version 25. Dichotomous variables were compared using Pearson's chi-squared test. For every continuous variable, the Kolmogorov-Smirnov test was used to determine whether the values were normally distributed. Normally distributed continuous variables were compared using ANOVA and the mean value was described in the results. If the variable was not normally distributed, the Kruskal-Wallis test was used and the median value described in the results. Reintervention-free survival analysis was performed using a Kaplan-Meier curve. We used a log-rank test to assess differences in reintervention-free survival. Test results with a $p$-value $<0.05$ were considered significant.

\section{Results}

\section{Study population}

A total of 206 patients ( $67 \%$ male) had a follow-up of at least 7 years. Patient characteristics are summarised in Tab. 1. Associated cardiac defects were reported in 147 patients (ventricular septal defect [38\%], bicuspid aortic valve [39\%], patent ductus arteriosus [21\%] and hypoplastic aortic arch [21\%]) and 114 (55\%) patients had haemodynamically significant comorbidities. Two thirds of patients were treated in the first three months of life. Median age at intervention was 30 days (range 2-6413). Surgical treatment was performed in 177 patients (75 with end-to-end anastomosis, 29 with extended end-to-end anastomosis, 33 with patch angioplasty through lateral thoracotomy without use of extracorporeal circulation, 37 with aortic arch reconstruction through median sternotomy with use of extracorporeal circulation, hypothermia and selective antegrade cerebral perfusion and 3 with interposition graft) and catheter-based intervention in 29 patients (6 with and 23 without stent) (Fig. 1; Tab. 2). Median age at follow-up was 15.5 years (range 7-35). Interval between initial intervention and last follow-up was 151 (range 75-347) months. CT or magnetic resonance imaging was performed in $42 \%$ of patients after a minimum follow-up of 7 years. All of the 127 patients ( 11 adults and 116 children) who did not have CT or magnetic resonance imaging under- 
Table 1 Baseline characteristics of the study population

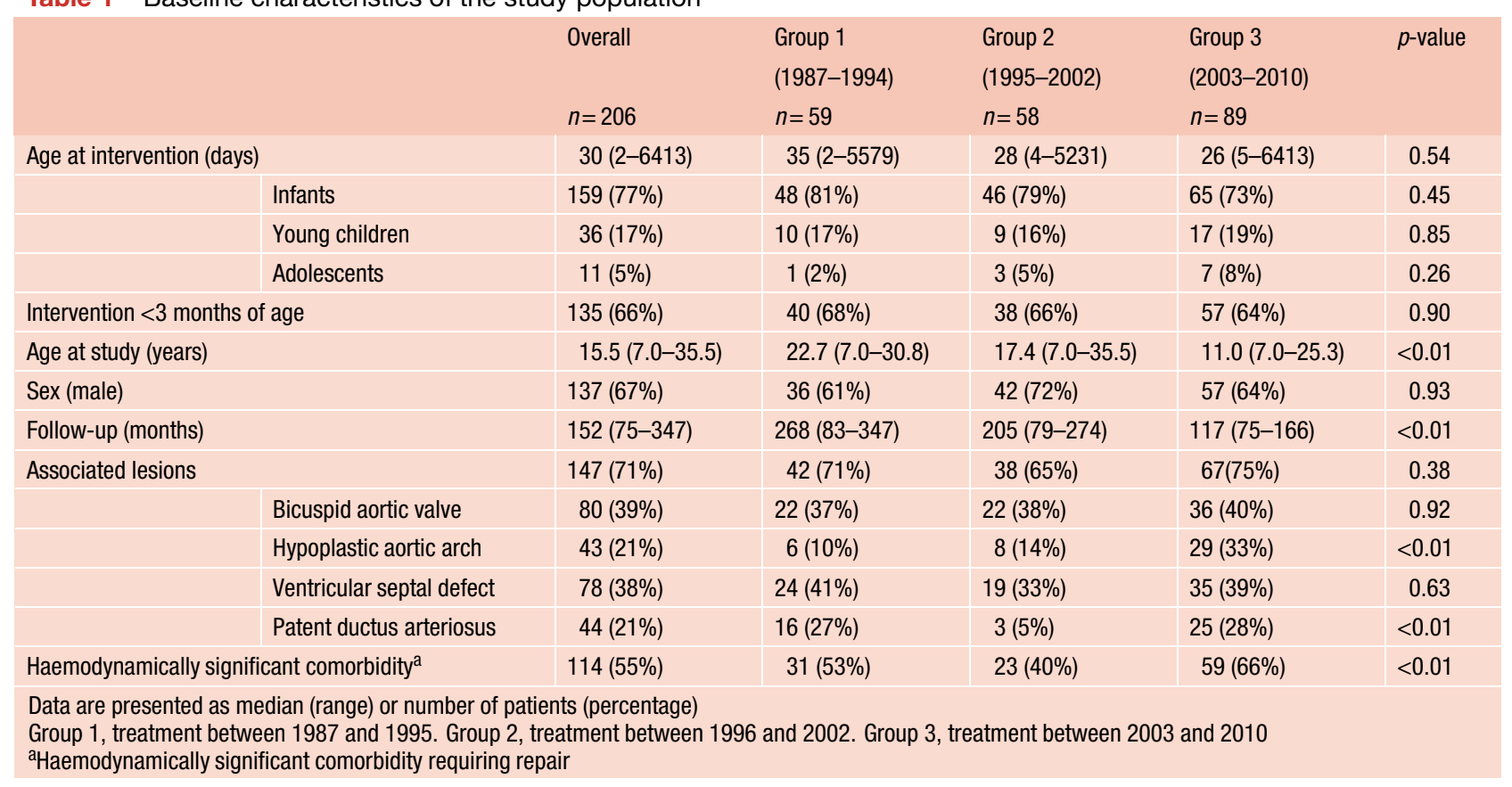

Table 2 Treatment strategies used for primary treatment

\begin{tabular}{|c|c|c|c|c|c|}
\hline & Overall & $\begin{array}{l}\text { Group } 1 \\
(1987-1994)\end{array}$ & $\begin{array}{l}\text { Group } 2 \\
\text { (1995-2002) }\end{array}$ & $\begin{array}{l}\text { Group } 3 \\
(2003-2010)\end{array}$ & $p$-value \\
\hline & $n=206$ & $n=59$ & $n=58$ & $n=89$ & \\
\hline End-to-end anastomosis & $104(50 \%)$ & $25(42 \%)$ & $31(54 \%)$ & $48(54 \%)$ & 0.34 \\
\hline Patch angioplasty & $33(16 \%)$ & $25(42 \%)$ & $6(10 \%)$ & $2(2 \%)$ & $<0.001$ \\
\hline Aortic arch reconstruction & $37(18 \%)$ & $2(4 \%)$ & $6(10 \%)$ & $29(33 \%)$ & $<0.001$ \\
\hline Interposition graft & $3(1 \%)$ & - & - & $3(3 \%)$ & NA \\
\hline Balloon angioplasty alone & $23(11 \%)$ & $7(12 \%)$ & $15(26 \%)$ & $1(1 \%)$ & $<0.001$ \\
\hline Balloon + stent placement & $6(3 \%)$ & - & - & $6(7 \%)$ & NA \\
\hline
\end{tabular}

went echocardiographic imaging of the aorta to assess aneurysm formation.

\section{Treatment}

Data on CoA treatment in the three different treatment eras are presented in Tab. 2. The number of patients increased significantly over the years. Recently, more patients were treated for hypoplastic arch $(p=0.001)$ and had associated cardiac defects $(p=0.006)$. Mean age at initial intervention decreased from 30 to 26 days ( $p=0.54$ ) and overall two thirds of patients were treated in the first three months of life. Tab. 3 provides data on treatment strategies (surgery versus endovascular treatment) over the different age groups at time of treatment.

\section{Follow-up}

Data on long-term follow-up is presented in Tab. 4.

\section{Reintervention}

Reinterventions were reported in 83 (40\%) patients: residual or recoarctation in 78 and aortic aneurysm in 5 patients. The interval between initial treatment and first reintervention ranged from 0.2 to 322 months. Event-free survival was $74 \%$ at 5-year and $68 \%$ at 10 -year follow-up, irrespective of treatment era ( $p=0.11$ and $p=0.16$ respectively). Patients who had a catheter-based intervention (with or without stent placement) had a significantly higher risk of reintervention compared with surgically treated pa-

Table 3 Treatment strategies used in different age groups at time of treatment

\begin{tabular}{|c|c|c|c|}
\hline & $\begin{array}{l}\text { Overall } \\
n=206\end{array}$ & $\begin{array}{l}\text { Surgery } \\
n=177\end{array}$ & $\begin{array}{l}\text { Endovascular } \\
n=29\end{array}$ \\
\hline Infant (0-1 yr) & 159 & $150(94 \%)$ & $9(6 \%)$ \\
\hline Young (1-10yr) & 36 & $22(61 \%)$ & $14(39 \%)$ \\
\hline Adolescent (10-18yr) & 11 & $5(45 \%)$ & $6(55 \%)$ \\
\hline
\end{tabular}


Fig. 1 Various treatment strategies over the years. (e)ETE (extended) end-toend anastomosis, $P A$ patch angioplasty, $A R$ aortic arch reconstruction, $B A$ balloon angioplasty

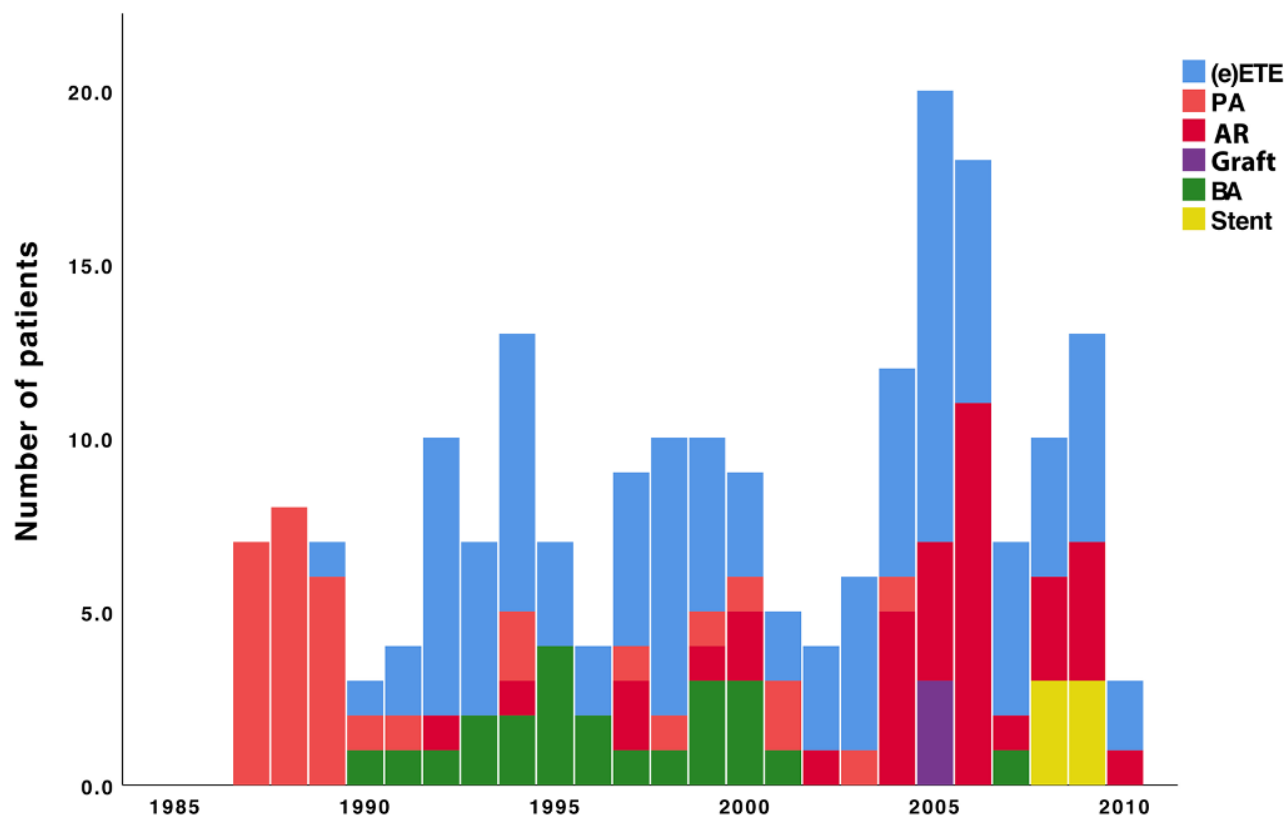

Year of primary intervention

tients (hazard ratio [HR] 1.8, 95\% confidence interval [CI] 1.04-3.00, $p=0.04$ )

At 10 -year follow-up, event-free survival was $71 \%$ for surgically treated patients compared with $50 \%$ for patients with catheter-based interventions $(p=0.03)$. Differences in reintervention rates across the different treatment periods were not statistically significant ( $p=0.07$ ) (Fig. 2). Patients treated before 3 months of age had a significantly higher risk of reintervention compared with patients treated later in life (HR 2.1, 95\% CI 1.27-3.55, $p=0.003$ ) (Fig. 3).

\section{Hypertension}

Hypertension was reported in 42 (20\%) patients with equal prevalence across the three treatment periods $(p=0.35)$. It occurred often in catheter-based interventions compared to surgical interventions (38\% versus $18 \%$, respectively, $p=0.01$ ).

\section{Aneurysms}

In 86 patients in whom the aortic arch was studied with CT or magnetic resonance imaging, aneurysm formation was described in 7 (8\%) patients, of which
5 had aneurysm formation after primary treatment (1 patch angioplasty, 2 end-to-end anastomosis and 2 catheter-based) and 2 after reintervention (both catheter-based). Five aneurysms required reintervention ( 2 surgical and 3 catheter-based). No differences in prevalence of aneurysm formation were found between the different treatment periods $(p=0.80)$.

\section{Discussion}

\section{Treatment}

We found that over time the number of patients had increased. The cause of this increase is possibly attributed to changes in patient referral and improved diagnostics [10-12].

In contrast to patients treated in the early era in whom resection and end-to-end anastomosis was the favoured approach, recently performed operations were done through a median sternotomy with the use of extracorporeal circulation, hypothermia and selective antegrade cerebral perfusion, and confined to

Table 4 Long-term outcome after treatment of native coarctation of the aorta

\begin{tabular}{|c|c|c|c|c|c|c|}
\hline & & $\begin{array}{l}\text { Overall } \\
(n=206)\end{array}$ & $\begin{array}{l}\text { Group } 1 \\
(n=59)\end{array}$ & $\begin{array}{l}\text { Group } 2 \\
(n=58)\end{array}$ & $\begin{array}{l}\text { Group } 3 \\
(n=89)\end{array}$ & $P$-value \\
\hline \multicolumn{2}{|l|}{ Reintervention } & $83(40 \%)$ & $21(36 \%)$ & $31(53 \%)$ & $32(36 \%)$ & 0.07 \\
\hline \multicolumn{2}{|l|}{ Hypertension } & $42(20 \%)$ & $14(24 \%)$ & $14(24 \%)$ & $14(16 \%)$ & 0.35 \\
\hline \multicolumn{7}{|c|}{ Aneurysm formation } \\
\hline & CT or MR imaging & $86(42 \%)$ & $35(59 \%)$ & $30(52 \%)$ & $21(24 \%)$ & $<0.01$ \\
\hline & Aneurysm found & $7(8 \%)$ & $2(6 \%)$ & $3(10 \%)$ & $2(10 \%)$ & 0.80 \\
\hline
\end{tabular}


Fig. 2 Kaplan-Meier curve showing reinterventionfree survival in the different treatment periods. Blue line: Group 1 (1987 and 1995). Red line: Group 2 (1996 and 2002). Green line: Group 3 (2003 and 2010). Black line: mean reintervention-free survival $(p=0.07)$

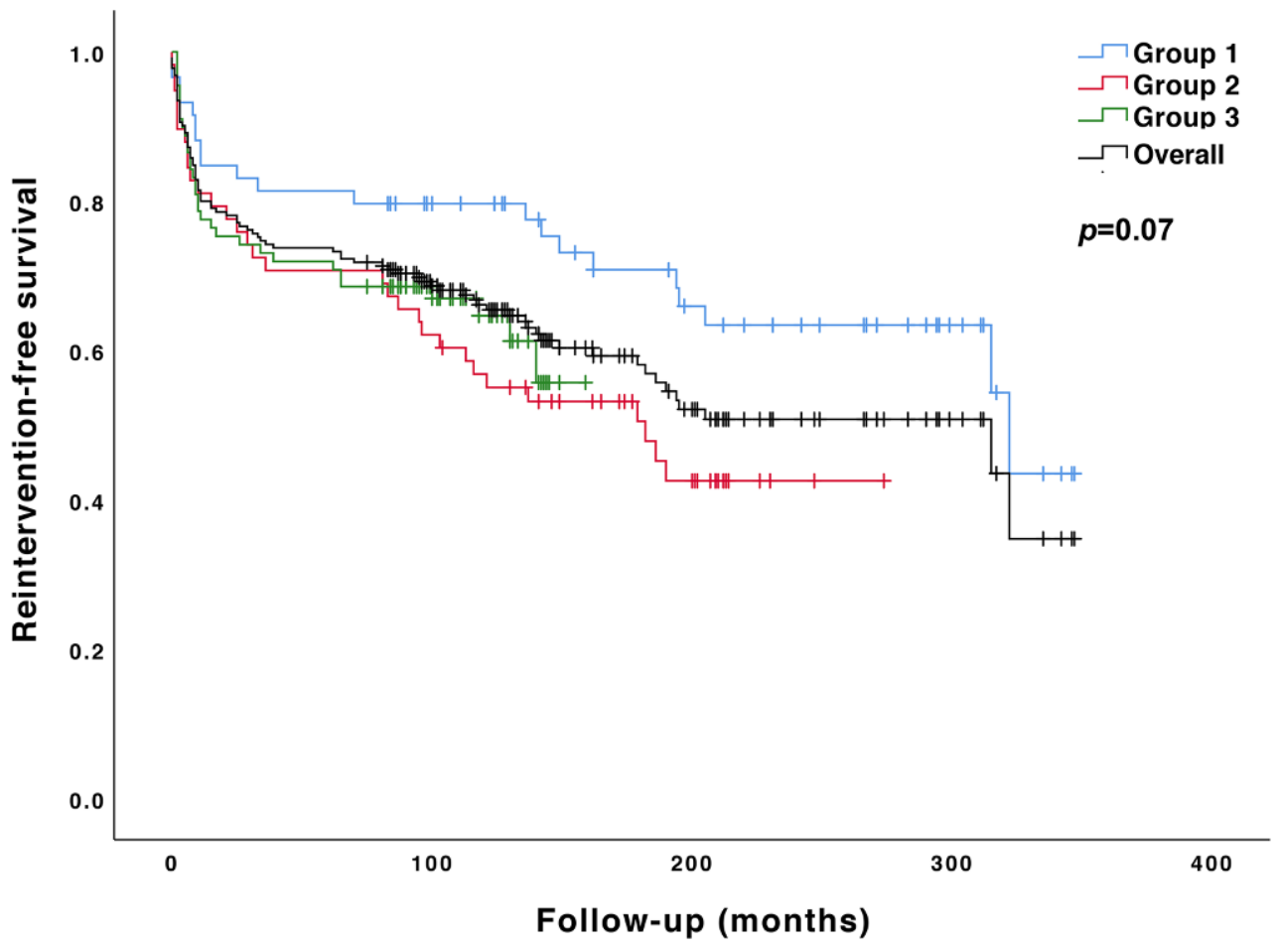

Fig. 3 Kaplan-Meier curve of the reintervention-free survival in patients comparing treatment $<3$ (b/ue line) and $>3$ months of age (red line) $(p<0.01)$

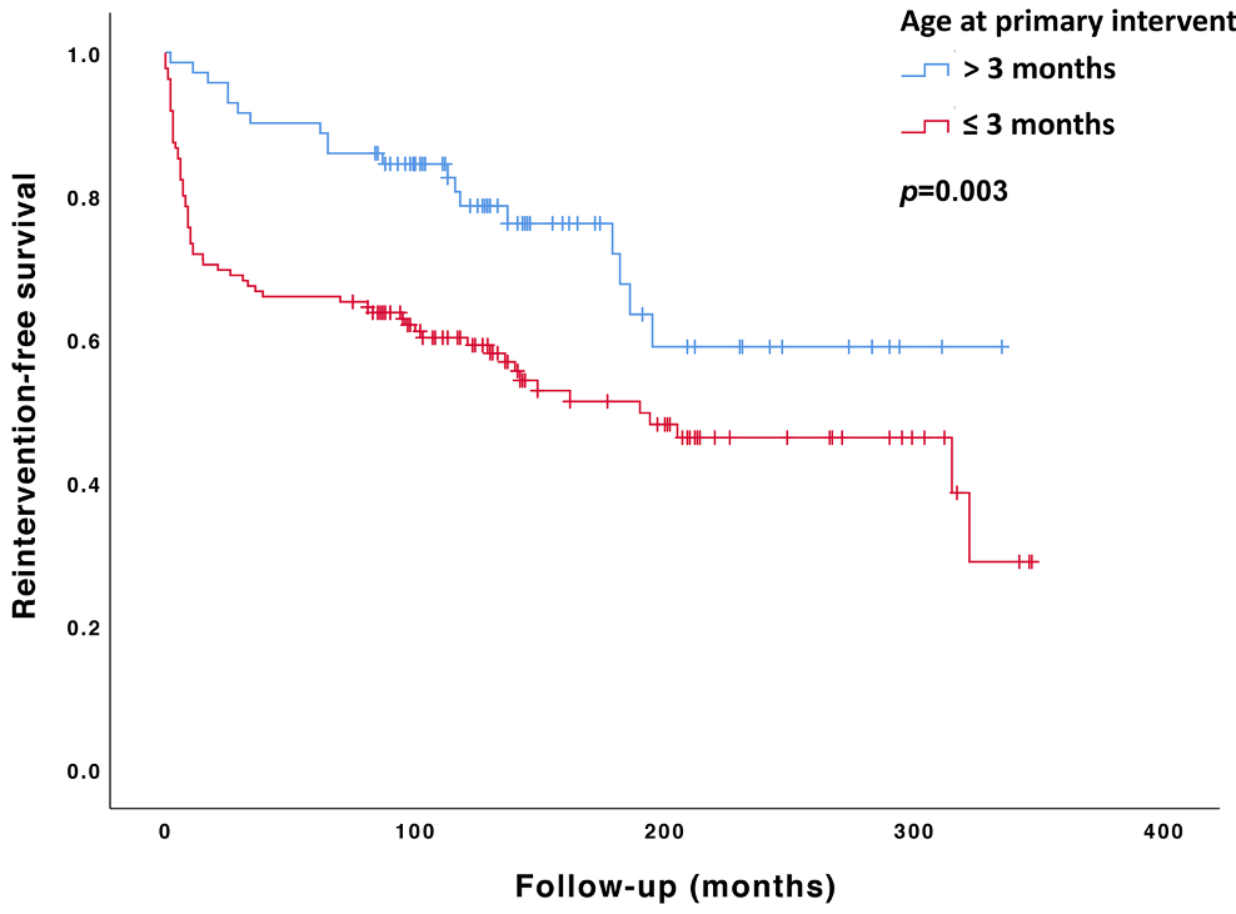

patients with arch hypoplasia and associated cardiac lesions.

In the past, the aortic arch was expected to show catch-up growth after single end-to-end anastomosis [13]. However, this did not appear to happen consistently [14]. Moreover, whether the aortic arch grows with the patient after CoA repair might be related to the extent of arch hypoplasia [15]. Several studies have assessed growth of the aortic arch after isolated end- to-end repair of CoA in association with arch hypoplasia and found that normal blood flow over the former coarctation site does not always guarantee normal aortic arch growth afterwards [14, 15]. Therefore, the threshold to concomitantly address the arch has become lower. This more radical approach is reflected in our study group.

Balloon angioplasty was introduced as an alternative therapy to surgery in the 1980s [16]. Thought to 
be a saver and less invasive treatment modality, balloon angioplasty was widely used for repair of CoA. However, after long-term follow-up, several studies showed that balloon angioplasty was associated with a higher incidence of aneurysm formation and recoarctation causing it to fall from grace as treatment for native CoA $[15,17,18]$. More recently, endovascular stent placement has been introduced. Stent placement is thought to have the benefits of balloon angioplasty (i.e. a less invasive treatment), but lower rates of recoarctation due to the stiff stent material placed at the coarctation site [19]. However, stent implantation in young children remains controversial, as it requires frequent redilatation to accommodate the growing aorta. Furthermore, stent placement in young children is associated with a high incidence of intimal proliferation and restenosis and a risk of poststent aneurysm formation [20]. Therefore, stent placement is reserved as a treatment for older children with no concomitant cardiac morbidity, as is reflected in our study group. Despite improved diagnosis, age at referral did not change over time and was similar in all 3 eras.

\section{Follow-up}

Residual lesions were a frequent cause of reintervention with a $68 \%$ event-free survival at 10 -year followup. In catheter-based (both balloon angioplasty and stent placement) treated patients, the rate of reintervention was higher. Explanatory, pioneer experience with exclusive use of balloon dilatation without the use of stent may have caused this high rate of reinterventions [15, 17, 21]. Supplemental stenting was only introduced in 2008. Apparently, dilatation of the coarctation is less effective than surgical repair, as reinterventions after surgery were less common. Modification of surgical technique from lateral approach without extracorporeal circulation to anterior approach with extracorporeal circulation did not change reintervention rates over time. Our reintervention rates of $40 \%$ are comparable with other studies $[1,2,4,7,19]$. However, in the available literature reintervention rates vary widely.

Brown et al. described reintervention rates of 7.2 , 14.3 and $23.4 \%$ at 10,20 and 30 years after initial surgical treatment in a cohort of 819 patients treated at a mean age of 17 years [22]. In contrast, Choudhary et al. showed a reintervention rate of $31 \%$ in patients treated surgically at a mean age of 5 years, with a follow-up of 26 years [7]. Our relatively higher reintervention rates might be explained by a younger age at intervention in our cohort. Repair before the age of 1 year has been identified as a risk factor for recoarctation and reintervention [6, 22]. Indeed, our study confirms a significant risk of reintervention for patients treated before 3 months of age.

Hypertension occurred more often in patients following catheter-based intervention compared with surgery. Comparative data on hypertension in longterm follow-up is very limited. Chiu et al. described equal prevalence of hypertension in surgical and catheter-based interventions at 10-year follow-up. However, the lack of baseline patient characteristics prevented further comparison of the results [23]. Older age at time of intervention has been identified as a risk factor for hypertension in long-term followup [24]. Given that a large number of the patients with a catheter-based intervention were treated at older age, this might explain the observed difference in prevalence of hypertension.

We observed a low rate of CT and magnetic resonance imaging across the study population, especially in the most recent era, which may have resulted in a relatively low rate of aneurysm formation in our study group. The lack of CT and magnetic resonance imaging might be explained by the fact that these patients have not yet reached adulthood, resulting in a large number of patients who only received echocardiographic imaging during follow-up. Nevertheless, the most recent guidelines suggest that magnetic resonance (or if necessary CT) imaging should be performed at least every 5 years as soon as the patients is old enough to undergo scanning without the need for sedation [11]. Furthermore, in a smaller substudy on long-term outcome ( $>10$ years) after coarctation repair, we found that many patients after coarctation treatment had been lost to follow-up [25]. In several of these patients, magnetic resonance imaging revealed recoarctation or aneurysm formation. Our current data show that the need for reintervention persisted up to 26 years after initial treatment, underscoring the importance of continued follow-up.

\section{Limitations}

Comparison of the different treatment periods might be influenced by differences in length of follow-up. Secondly, data collection was restricted to the available information in the patients' medical records, resulting in some incomplete data for the assessed parameters.

\section{Conclusion}

Coarctation treatment strategy has changed over time: nowadays coarctectomy is performed on pump with aortic arch enlargement with concomitant repair of associated lesions, whereas in older patients with simple coarctation balloon dilatation and stenting has become our preferred approach. Reintervention was required in $40 \%$ of patients and was more frequent after catheter-based interventions. Hypertension was present in one out of five patients and more frequent after catheter-based interventions. Our results underscore the importance of regular follow-up with adequate imaging throughout childhood and adulthood after successful repair of aortic coarctation. 
Funding This study was funded by a grant from the Dutch Hartekind Foundation ("Stichting Hartekind").

Conflict of interest E.J. Dijkema, L. Dik, J.M.P. Breur, G.T. Sieswerda, F. Haas, M.G. Slieker and P.H. Schoof declare that they have no competing interests.

Open Access This article is licensed under a Creative Commons Attribution 4.0 International License, which permits use, sharing, adaptation, distribution and reproduction in any medium or format, as long as you give appropriate credit to the original author(s) and the source, provide a link to the Creative Commons licence, and indicate if changes were made. The images or other third party material in this article are included in the article's Creative Commons licence, unless indicated otherwise in a credit line to the material. If material is not included in the article's Creative Commons licence and your intended use is not permitted by statutory regulation or exceeds the permitted use, you will need to obtain permission directly from the copyright holder. To view a copy of this licence, visit http://creativecommons.org/licenses/by/4.0/.

\section{References}

1. Canniffe C, Ou P, Walsh K, et al. Hypertension after repair of aortic coarctation-A systematic review. int J Cardiol. 2013;167:2456-61.

2. Rosenthal E. Coarctation of the aorta from fetus to adult: Curable condition or life long disease process? Heart. 2005;91:1495-502.

3. TorokRD, Campbell MJ, Fleming GA, Hill KD. Coarctation of the aorta: Management from infancy to adulthood. World J Cardiol. 2015;7:765-75.

4. Crafoord C, Nylin G. Congenital coarctation of the aorta and its surgical treatment. J Thorac Cardiovasc Surg. 1945;14:347-61.

5. Singer M, Rowen M, Dorsey TJ. Transluminal aortic balloon angioplasty for coarctation of the aorta in the newborn. Am HeartJ. 1982;103:131-2.

6. Dijkema EJ, Leiner T, Grotenhuis HB. Diagnosis, imaging and clinical management of aortic coarctation. Heart. 2017;103:1148-55.

7. Choudhary P, Canniffe C, Jackson DJ, et al. Late outcomes in adults with coarctation of the aorta. Heart. 2015;101:1190-5.

8. Moulaert AJ, Bruins CC, Oppenheimer-Dekker A. Anomalies of the aortic arch and ventricular septal defects. Circulation. 1976;53:1011-5.

9. Wühl E, Witte K, Soergel M, et al. Distribution of 24-h ambulatory blood pressure in children: normalized reference values and role of body dimensions. J Hypertens. 2002;20:1995-2007.

10. Erbel R, Aboyans V, Boileau C, et al. 2014 ESC guidelines on the diagnosis and treatment of aortic diseases. Eur Heart J. 2014;35:2873-926.

11. Stout KK, Daniels CJ, Aboulhosn JA, et al. 2018 AHA/ACC Guideline for the Management of Adults With Congenital
Heart Disease: A Report of the American College of Cardiology/American Heart Association Task Force on Clinical Practice Guidelines. Vol 139. 2019. https://doi.org/10. $1161 /$ CIR.0000000000000603

12. Rothman A. Coarctation of the aorta: an update. Curr Probl Pediatr. 1998;28:37-60. https://www.ncbi.nlm.nih.gov/ pubmed/23440940.

13. Brouwer M, Cromme-Dijkhuis A, Ebels T, Eijgelaar A. Growth of the hypoplastic aortic arch after simple coarctation resection and end-to-end anastomosis. J Thorac Cardiovasc Surg. 1992;104:426-33.

14. Meyers J, McConnell B, Waldhausen J. Coarctation of the aorta in infants: does the aortic arch grow after repair? Ann Thorac Surg. 1992;54:869-75.

15. Fiore AC, Fischer LK, Schwartz T, et al. Comparison of angioplasty and surgery for neonatal aortic coarctation. Ann Thorac Surg. 2005;80:1659-65.

16. Lock JE, Niemi T, Burke BA, et al. Transcutaneous angioplasty of experimental aortic coarctation. Circulation. 1982;66(6 I):1280-6.

17. Cowley CG, Orsmond GS, Feola P, et al. Long-term, randomized comparison of balloon angioplasty and surgery for native coarctation of the aorta in childhood. Circulation. 2005;111:3453-6.

18. Hernández-González M, Solorio S, Conde-Carmona I, et al. Intraluminal aortoplasty vs. surgical aortic resection in congenitalaortic coarctation. A clinical random study in pediatric patients. Arch Med Res. 2003;34:305-310.

19. Forbes TJ, Kim DW, Du W, et al. Comparison of surgical, stent, and balloon angioplasty treatment of native coarctation of the aorta: An observational study by the CCISC (Congenital cardiovascular interventional study consortium). JAm Coll Cardiol. 2011;58:2664-74.

20. Früh S, Knirsch W, Dodge-Khatami A, et al. Comparison of surgical and interventional therapy of native and recurrent aortic coarctation regarding different age groups during childhood. Eur J Cardio-thoracic Surg. 2011;39:898-904.

21. Hernandez-Gonzalez M, C-CI SS. Conde-Carmona I, et al. Intraluminal aortoplasty versus surgical aortic resection in congenital aortic coarctation. A clinical random study in paediatric patients. Arch Med Res. 2003;34:305-10.

22. Brown ML, Burkhart HM, Connolly HM, et al. Coarctation of the aorta: Lifelong surveillance is mandatory following surgical repair. JAm Coll Cardiol. 2013;62:1020-5.

23. Chiu HH, Chiu SN, Hu FC, et al. Late Cardiovascular Complications After Surgical or Balloon Angioplasty of Coarctation of Aorta in an Asian Cohort. am J Cardiol. 2009;104:1139-44.

24. Kenny D, Polson JW, Martin RP, et al. Hypertension and coarctation of the aorta: An inevitable consequence of developmental pathophysiology. Hypertens Res. 2011;34:543-7.

25. Dijkema EJ, Sieswerda GT, Takken T, et al. Long-term results of balloon angioplasty for native coarctation of the aorta in childhood in comparison with surgery. Eur J Cardiothoracic Surg. 2018;53:262-8. 